a programme of scientific teaching in the former Pasteur Institutes or other institutes. This is run by scientists from the Pasteur Institute in Paris. Microbiology is taught at the Pasteur Institute in Algiers, immunology at the Pasteur Institute in Tunis, immunology and virology in Hanoi and Ho-Chi-Minh-ville. Further technical co-operation includes mycological research and the biological control of disease vectors in Mexico, teaching molecular genetics in Brazil, molecular biology in Venezuela, genetic engineering in China and mycology and bacteriology in Kuala Lumpur (Tropmed).

\section{Research programmes applied to local public health problems}

Because of limitations in research grants, the Delegation for Overseas Pasteur Institutes has to co-ordinate research programmes. In effect this is done by three steering committees composed of specialists from many countries. The three top priorities at present are leprosy, parasitology and virology which will encompass immunology, biochemistry and molecular biology as well as medical and epidemiological studies. Parts of these programmes are carried out overseas and parts in Paris.

In addition to surveillance and control activities, there are four programmes in leprosy. The armadillo, which is one of the rare animal models available to study the infection, provides enough antigen at the Pasteur Institute in Cayenne (French Guyana) for studies in Paris, Dakar, Tahiti, Noumea and Guadeloupe. Man's specific and non-specific cellular and humoral responses to infection and their modifications under chemotherapy and chemoprophylaxis are studied in Cayenne and Dakar. Transmission of leprosy and immunogenetic factors are studied in Cayenne. Drugs and resistance are studied in Guadeloupe, French Guyana, Tahiti and New Caledonia.

Parasitologists are mainly concerned with studies on malaria, leishmaniasis and Wuchereria bancrofti filiariasis. Saimiri monkeys available in French Guyana provide the malaria antigen of Plasmodium falciparum and $P$. vivax. The immune response of this monkey is studied at Cayenne and of man at Dakar and Paris. Cutaneous and sub-cutaneous (kala azar) leishmaniasis are studied at Dakar and Cayenne, and the membrane proteins are studied in the Pasteur Institutes of Athens and Paris, in collaboration with Brazil and Bolivia. Scientists studying $W$. bancrofti filiariasis in Tahiti have disclosed some of the immune mechanisms which control the microfilariema.
The forest life cycle of yellow fever, dengue and other arboviruses is studied by virologists at the Pasteur Institutes in Dakar, Abidjan, Bangui and Cayenne. Dengue is also studied in Tahiti and Noumea where outbreaks have recently occurred. The molecular structure of yellow fever virus and its possible application to vaccine preparation and specific diagnosis is studied in Dakar. Haemonhagic fevers caused by Lassa, Marburg and Ebola viruses are studied in Dakar, Abidjan and Bangui. Indeed, the Pasteur Institute in Dakar is a regional WHO Collaborating Centre for arboviruses. The differences between rabies viruses are studied in the Pasteur Institute in Paris in collaboration with the Institutes in Dakar, Abidjan, Bangui, Tananarive, Tunis and Casablanca.

Other diseases of public health importance are also subject to study: diarrhoeas, viral hepatitis, Burkitt's lymphoma, respiratory infections and genetic diseases (drepanocytosis (sickle cell anemia) in Guadeloupe and diabetes in Noumea).

\section{Future trends}

The flexible formula adopted to maintain the Pasteur Institutes after 1960 has proved its worth. The resulting heterogeneity of structure does not adversely affect the work of the institutes. However, the increasing sophistication of research necessitates a close co-ordination of the work of the various Institutes. Training and technical sup port are essential for maintaining an adequate level of reseanch. Scientists are trained locally and at the Pasteur Institute in Paris where they graduate in the same way as their French colleagues. Refresher training is ensured through a turnover of assignments in Paris and overseas. Part of the expatriate scientific personnel (more than 50) is loaned by the Army, others belong to the scientific staff of the Pasteur Institute in Paris and have a contract stating that they should spend $60 \%$ of their time overseas and $40 \%$ of their time in Paris. Grants are received from different French ministries and a few from international agencies. However, as local resources are added to grants it is not possible to evaluate the total budget available to all the institutes.

Pasteur's idea has survived him for more than 90 years. The cement of this network is a common education, a common dedication, a common philanthropy and the prestige of a name.

\title{
Is superoxide important in oxygen poisoning?
}

\section{James A. Fee}

That the hypothesis of superoxidemediated oxygen toxicity, formulated in $1971^{1}$, has failed to gain a coherent, generally verifiable experimental foundation has recently been discussed in a number of specialized communications ${ }^{2-5 *}$. I should like to inform a more general audience of what I believe are important shortcomings of the hypothesis, and to recall an older one $^{6}$ which now appears to offer real hope for understanding oxygen poisoning at the molecular level. Controversy in this field originates mainly from differences in the interpretation of empirical facts and the relative weights they contribute to assessing the correctness of the superoxide

*This brief discussion is abstracted from Refs 2-5 which may be consulted for references to the original literature.

James A. Fee is at the Deparment of Biological Chemistry and Biophysics Research Division, The University of Michigan, Ann Arbor, MI 48109, U.S.A. hypothesis and to a lesser extent from disagreement over the validity of experimental observations. Let us begin by recounting the basic premises of the superoxide paradigm and describing the areas of agreement and disagreement.

The hypothesis ${ }^{1}$ that superoxide mediates oxygen toxicity is predicated on three essential ideas which can be transliterated into some simple chemical processes. First, superoxide is formed by aerobic organisms. Second, superoxide is in some manner toxic to the cell. Third, superoxide dismutases exist for the essential purpose of eliminating superoxide. These concepts can be written as exemplary chemical reactions:

$$
\begin{gathered}
\mathrm{X}+\mathrm{O}_{2} \rightarrow \mathrm{X}^{+}+\mathrm{O}_{2}^{-} \\
\mathrm{O}_{2}^{-}+\mathrm{H}_{2} \mathrm{O}_{2}+\mathrm{H}^{+} \rightarrow \mathrm{O}_{2}+\mathrm{H}_{2} \mathrm{O}+\mathrm{OH} \cdot \\
2 \mathrm{O}_{2}^{-}+2 \mathrm{H}^{+} \rightarrow \mathrm{O}_{2}+\mathrm{H}_{2} \mathrm{O}_{2}
\end{gathered}
$$

In Reaction [1] a single electron is transferred to ground-state dioxygen from an unspecified compound, $X$, to form 
superoxide and an oxidized substance, $\mathrm{X}^{+}$. Superoxide has been detected during the autoxidation of a variety of well defined substances as well as complex systems, including whole cells. Thus, there exists a body of literature which fully supports the concept that superoxide is a minor but significant product of the aerobic lifestyle. Controversy arises from disagreement over the subsequent actions of superoxide, and in recent times little attention has been given to the other product of Reaction [1], $\mathrm{X}^{+}$

In spite of extensive efforts by chemists and biochemists alike, no direct reaction of aqueous superoxide with a cellular substance has been discovered which can be even remotely considered to account for the toxicity of oxygen. Moreover, the chemistry of superoxide, which is now quite well understood, holds little hope for finding such a reaction ${ }^{7,8}$. Nevertheless, a significant number of destructive processes involving both superoxide and hydrogen peroxide have been reported which are best understood in terms of hydroxyl radical production as shown by Reaction [2], and supporters of the superoxide hypothesis appear to have settled on this reaction as a molecular basis of superoxide toxicity ${ }^{9}$. Cerainly, everyone agrees that $\mathrm{OH}^{*}$ has the necessary chemical reactivity to destroy biological molecules rapidly and indiscriminately.

However, before Reaction [2] slips into symbolic use as the origin of oxygen toxicity there are some important features of this process which need thorough consideration: (a) as written, the reaction does not occur; (b) the reaction can be catalyzed by various transition metal ions, e.g. iron, in which case it must be written as a composite of reaction [4] and the Fenton reaction, [5]

$\mathrm{O}_{2}^{-}+\mathrm{Fe}$ (III) $\rightarrow \mathrm{O}_{2}+\mathrm{Fe}$ (II)

$\mathrm{Fe}(\mathrm{II})+\mathrm{H}_{2} \mathrm{O}_{2} \rightarrow \mathrm{Fe}(\mathrm{III})+\mathrm{H}_{2} \mathrm{O}+\mathrm{OH} \cdot[5]$

the sum of which is Reaction [2] and; (c) in the composite reaction, the sole function of $\mathrm{O}_{2}{ }^{-}$is to act as a one electron reductant of the higher valent form of the metal ion. While there is no disagreement that reactions [4] and [5] occur in vitro, where trace metal contaminants abound, there is disagreement on whether this process occurs in vivo.

Reaction [3] occurs spontaneously with a second-order rate constant of $10^{5} \mathrm{M}^{-1} 1 \mathrm{~s}^{-1}$ at $\mathrm{pH} 7$ and is catalyzed by a variety of coordination complexes of $\mathrm{Cu}, \mathrm{Fe}$, and $\mathrm{Mn}^{10}$. Within some cells the reaction is clearly catalyzed by superoxide dismutases, metalloproteins characterized by binding $\mathrm{Cu}, \mathrm{Fe}$, or $\mathrm{Mn}$ ions. It has been concluded from various biological studies that superoxide dismutases provide 'a first line of defense' against the toxicity of oxygen. However, when all relevant observations are examined thoroughly I think such a conclusion is not justified. Thus, while there is agreement that superoxide dismutases exist within many cells and that they catalyze Reaction [3]; there is disagreement on whether this activity provides protection against oxygen poisoning.

To focus the controversy, let us consider three questions: (a) Is the formation of hydroxyl radical by superoxide mediated Fenton chemistry (Reactions [4] and [5]) responsible for $\mathrm{O}_{2}$ toxicity? (b) Do observations on the presence of superoxide dismutases in biological systems support the theory? (c) Should dioxygen itself be reconsidered as the source of $\mathrm{O}_{2}$ poisoning?

\section{Is $\mathrm{O}_{2}$ toxicity due to the combined action} of $\mathrm{O}_{2}^{-}, \mathrm{H}_{2} \mathrm{O}_{2}$, and metal ions?

There are compelling reasons why Reactions [4] and [5] must be regarded with great suspicion as an important mechanism of oxygen toxicity: Superoxide can be replaced by other reducing agents in reaction [4], thus,

$$
\mathrm{AH}_{2}+\mathrm{Fe}(\mathrm{III}) \rightarrow \mathrm{AH}_{2}{ }^{+}+\mathrm{Fe} \text { (II) [6] }
$$

and several recent studies have shown that a destructive process being effected via Reactions [4] and [5] can be made totally insensitive to inhibition by superoxide dismutase if Reaction [6] is begun as a parallel reaction $^{11,12}$. Thus, cellular reducing agents ${ }^{13}$ might be expected to completely override any contribution of [4] to the velocity of [5]. A second concern one must have is whether intracellular metal ions are free to participate in [5]. Indeed, there are good teleological reasons to suspect that Reaction [5] is very carefully controlled within the cell (probably by metal ion sequesteration), and the fact that some organisms grow in rather high concentrations of $\mathrm{H}_{2} \mathrm{O}_{2}$ tends to support this view. Finally, many symptoms of oxygen poisoning are rapidly reversible; this is not consistent with the wide spread damage anticipated from the occurrence of Reaction [5].

\section{Do observations of biological systems support the theory?}

The biological facts which tend to cast doubt on the original conclusions derived from surveys of various organisms, induction of superoxide dismutase under oxidizing conditions, and preliminary genetic studies are as follows: (a) Superoxide dismutases exist in a wide variety of strictly anaerobic organisms, and there is no obvious correlation between the amount of dismutase within a particular organism and its sensitivity to oxygen. (b) There are now four distinctly different, aerobic types of cells which lack superoxide dismutases
These are Lactobacillus plantarum ${ }^{\dagger}$, some strains of Neisseria gonnorhoea and of Mycoplasma, and adipocytes. These few examples are living proof that superoxide dismutase is not an essential requirement of the aerobic lifestyle. (c) Experiments showing that certain redox dyes, such as methylviologen, were capable of inducing the manganese form of dismutase in E. coli and that such cells were resistant to killing by hyperoxia ${ }^{15}$ are impossible to interpret in terms of a protective effect due to increased superoxide dismutase since neither hyperbaric oxygen nor aerobic methylviologen by themselves are lethal to $E$. coli ${ }^{16}$. Thus, the protection which was obtained against the killing of cells in the presence of puromycin (an inhibitor of protein synthesis) cannot be directly attributable to the increased level of superoxide dismutase. Indeed, Simons et $a l^{17}$ manipulated the superoxide dismutase levels by varying the concentrations of $\mathrm{Mn}$ and $\mathrm{Fe}$ in the culture media and found no difference in the degree of protection against the bactericidal mixture. Finally (d), the genetic experiments reviewed in Ref. 18 are internally inconsistent and do not support the idea that either manganese- or iron-superoxide dismutase offer protection against oxygen poisoning in $E$. coli. In summary, the biological experiments cannot be rationalized with the widely accepted view that superoxide dismutases protect an organism from oxygen.

\section{Should dioxygen itself be reconsidered as} an important element of oxygen toxicity?

The free radical theory of oxygen toxicity ${ }^{19}$, of which the superoxide hypothesis is but a part, holds that superoxide and the other reduced forms of oxygen which derive from it are responsible for oxygen poisoning. Unfortunately, after some 25 years of invoking free radicals as the source of oxygen poisoning there is no proof they are causative agents $\ddagger$, and alternative hypotheses need to be entertained.

One of the shortcomings of the free radical theory is that by focussing attention on the reduced forms of oxygen, inadequate attention has been paid to the nature of the

tThe recent claim that this organism accumulates high levels of $\mathrm{Mn}$ (II), which itself possesses a weak dismutase-like activity, for the purpose of dismuting $\mathrm{O}_{2}{ }^{-}$seems improbable in view of the fact that $\mathrm{Mn}$ (II) is required for transcription in lactobacilli ${ }^{14}$.

\$The free radical theory is obviously important in considerations of biological oxidations. Some examples of free-radical mediated oxygen toxicity are lipid peroxidation, oxygen dependent destructive activities of certain macrophages, and the effects of some redox active drugs, such as dialuric acid, on various tissues, However, these processes are clearly not the primary events of oxygen poisoning, and the participation of superoxide is certainly not established 
other participants in Reaction [1]. However, prior to the popularization of the superoxide theory, extensive work had been done on the in vitro sensitivity of enzymes and other cell components to hyperbaric oxygen, and the prevailing theory was that enzymes were inactivated in vivo by oxygen. Thus, in Reaction [1], a critical enzyme, symbolized by $X$, would be inactivated $(X+)$, thereby disrupting the overall metabolism of the cell. Haugaard, who reviewed this literature in $1968^{6}$, gave two reasons the hypothesis did not gain wider acceptance: 'First, inactivation of enzymes in vitro appeared to be too slow in onset to account for the symptoms that occurred in the intact animal. Second, no conclusive demonstration had been made that any enzyme, in any organ of the intact animal, was inhibited during exposure of the animal to oxygen at an elevated pressure.' However, there are now several examples of enzymes which are rapidly and directly inactivated by dioxygen, and there are clear-cut demonstrations of enzyme inactivation in vivo. Two examples of enzymes inactivated in vivo, in the presence of superoxide dismutase, are amidophosphoribosyl transferase ${ }^{20}$ (purine biosynthesis) and dihydroxyacid dehydratase $^{21}$ (branched chain amino acid biosynthesis). These and other examples suggest the possibility that understanding oxygen toxicity will require sensitive enzymes be identified, isolated, and characterized in terms of their reactivity towands oxygen in much the same manner one would determine the mechanism of an enzyme

We are left with the question of why cells have superoxide dismutases. The following possibilities should be considered: (a) all superoxide dismutases are involved in protection of cells against oxygen toxicity; (b) superoxide is a metabolite whose concentration must be controlled; (c) superoxide dismutase activity is a trivial property of metalloproteins, inherent to the metal ion, and the real biological functions have not yet been discovered and; (d) combinations of the above.

In view of this discussion, possibility (a) seems unlikely. However, possibility (b) cannot be excluded, and certain observations suggest that $\mathrm{O}_{2}{ }^{-}$may play some role in the chemotactic response of macrophages $^{22}$. However, it is difficult to imagine why strictly anaerobic organisms which are highly sensitive to oxygen, such as the methanogens, express this type of activity. For some time the author has entertained possibility (c), however, there is no direct evidence in support of alternate functions for these proteins. It is hoped that genetic studies will shed light on this problem.
References

1 McCord, J. M., Keele, Jr., B. B. and Fridovich, I. (1971) Proc. Natl. Acad. Sci. U.S.A. 68, 1024-1027

2 Fee, J. A. in King, T. E., Mason, H. S. and Morrison, M. (eds) Oxidases and Related Systems Pergamon Press (in press) Presented at the Third International Symposium on Oxidases and Related Redox Systems, July 1-4, 1979, Albany, New York

3 Fee, J. A. (1980) in Metal Ion Activation of Dioxygen (Spiro, T., ed.), pp. 209-237, John Wiley and Sons, New York

4 Fee, J. A. (1981) in Oxygen and Oxy-radicals in Chemistry and Biochemistry (Rodgers, M. A. J and Powers, E. L., eds), pp. 205-221, Academic Press, New York

5 Fee, J. A. (1981) in Oyygen and Life Special Publication No. 39, pp. 77-97, The Royal Society of Chemistry, Burlington House, London

6 Haugaard, N. (1968) Physiol. Rev. 48, 3!1-373

7 Fee, J. A. and Valentine, J. S. (1977) in Superoxide and Superoxide Dismutases (Michelson. A. M., McCord, J. M. and Fridovich, I., eds), pp. 19-60 Academic Press, London

8 Bors, W., Saran, M. and Czapski, G. (1980) in Vol. I of Biological and Clinical Aspects of Superoxide and Superoxide Dismutases (Bannister, J. V. and Hill, H. A. O., eds), pp. 1-31, Elsevier/North-Holland Biomedical Press

9 Michelson, A. M., McCord, J. M. and Fridovich, I. (1977) in Superoxide and Superoxide Dis- mutases (Michelson, A. M., McCord, J. M. and Fridovich, I., eds), p. 320, Academic Press

$10 \mathrm{Fee}, \mathrm{J}$. A. in Metal Ions in Biological Systems (Sigel, H.. ed.), Vol. 13, pp. 259-298, Marcel Dekker, New York

11 Hofmann, H. and Schmutt, O. (1980) Graefes Arch. Opthalmol. 214, 181-185

12 Marshall, L. E., Graham, D. R., Reich, K. A. and Sigman, D. S. (1981) Biochemistry 20, 244-250

13 Archibald, F. S. and Fridovich, I. (1981) J. Bacteriol. $145,442-451$

14 Stetter, K. O. and Kandler, O. (1973) FEBS Lett $36,5-8$

15 Hassan, H. M. and Fridovich, I. (1977) J. Biol. Chem. 252, 7667-7672

16 Fee, J. A., Lees, A. C., Bloch, P. L., Gilliland, P. L. and Brown, O. (1980) Biochem. Int. 1, 304.311

17 Simons, R. S., Jackett, P. S., Carroll, M. E. W. and Lowrie, D. B. (1976) Toxicol. Appl. Pharmacol. 37, 271-280

18 Hassan, H. M. and Fridovich, I. (1979) Infect Dis, Rev. 1, 357-369

19 Gersham, R., Gilbert, D. L., Nye, S. W., Dwyer, P. and Fenn, W. O. (1954) Science 119, 623-626

20 Itakura, M. and Holmes, E. W. (1979) J. Biol. Chem. 254, 333-338

21 Brown, O. R. and Yein, F. (1978) Biochem. Biophys. Res. Commun. 85, 1219-1224

22 Petrone, W. F., English, D. K., Wong, K. and McCord, J. M. (1980) Proc. Natl. Acad. Sci. U.S.A. 77, 1159-1163

\title{
Opinion
}

\section{Validity of scientific data - the responsibility of the principal investigator}

\author{
Harvey F. Lodish
}

The complex rules that govern the practice of modern science are rarely set down in writing - at least not in a form which would be read by most practicing biochemists. They are passed - or should be - by example from mentor to $P h . D$. student, from lab director to research staff and fellows. To my mind the most important of these concerns the mechanisms by which one ensures that all published data are true and reliable, and can be used as a basis for further investigations by other laboratories.

The principal investigator (P.I.) must play the key role in this process. In most American universities and research institutes, this would be the actual P.I., the one who is the recipient of the grant which supports the work. In laboratories with other

Harvey F. Lodish is at the Department of Biology, Massachusetts Institute of Technology, Cambridge, MA 02139, U.S.A. organizational structures, this would be the person who actually directs the work in question, not necessarily the director of the entire laboratory. In practical terms, this would be the person who submits the paper to the journal, and who (generally) puts his or her name at the end of the list of authors. It is generally unreasonable to expect the Head of a Department, or Director of the Institute, to play an immediate role in the process of validation and verification, given the diverse types of projects and techniques that are underway in even most medium-sized departments or institutes.

Many of the recent scandals concerning forged or doctored data stem from the fact that most research groups tend to be rather large, and that the principal investigator or lab chief did not have a direct role in the supervision or conduct of the experiments. Biochemical methodology is evolving very rapidly. It is now very common for a Ph.D. 